\title{
Arte e tragédia: representações sobre a seleção brasileira de 1982 em livros do século XXI
}

\author{
Art and Tragedy: The Representations of the 1982 Brazilian National \\ Football Team in Books of the 21st Century
}

\begin{abstract}
Diano Albernaz Massarani
Universidade Federal Fluminense, Niterói, Rio de Janeiro/Brasil Doutorando em Antropologia, Universidade Federal Fluminense diano_am@yahoo.com.br
\end{abstract}

\begin{abstract}
Resumo: A história da seleção brasileira de futebol é marcada tanto por láureas como por derrotas que perduram no tempo e são frequentemente recontadas, como é o caso da Tragédia do Sarriá, nome dado à eliminação da seleção brasileira de 1982 da Copa do Mundo. Este artigo procura compreender a Tragédia do Sarriá como um dos eventos mais rememorados e intrigantes do futebol brasileiro, através da análise da construção de representações sobre o estilo de jogo da seleção brasileira de 1982, em livros publicados neste século que narram a trajetória desta equipe. Décadas após a Tragédia do Sarriá, a seleção brasileira de 1982 surge representada como a última seleção que praticou o futebol-arte, estilo de jogo tido como "genuinamente" brasileiro, sendo, por isso, vista como injustiçada pela não conquista do título da Copa do Mundo. Nesse processo construtivo, destaca-se a significativa participação da seleção brasileira campeã da Copa do Mundo de 1994 na posição de alteridade privilegiada.
\end{abstract}

Palavras-chave: Futebol-arte; Representações; Seleção brasileira de futebol; Tragédia do Sarriá.

ABSTRACT: The history of the Brazilian national football team is marked both by glories and defeats that last in time and are often retold, as is the case of the Sarriá's Tragedy, an event that marks the elimination of the 1982 Brazilian team from the World Cup. This paper aims to understand the Sarriá's Tragedyas one of the most memorable and intriguing episodes of the Brazilian football through an analysis of the construction of representations concerningthe play's style of the 1982 Brazilian team in books published in this century that narrate the trajectory of that team. Decades after the Sarriás Tragedy, the 1982 Brazilian team is represented as the last national team that practiced the football-arte, a style of play considered as "genuinely" Brazilian and, because of this, it is seen as wronged for not winning the title of the World Cup. In this constructive process, it is crucial to highlight the significant participation of the Brazilian team that won the World Cup in 1994 in the position of privileged otherness.

KEYWORDS: Football-art; Representations; Brazilian National Football Team; Sarriá's Tragedy. 


\section{INTRODUÇÃO}

A seleção brasileira de futebol, maior vencedora da Copa do Mundo e única a participar de todas as edições já realizadas do evento, apresenta uma trajetória repleta de láureas. Todavia, essa trajetória também é marcada por derrotas que perduram no tempo e são frequentemente recontadas em materiais produzidos por jornalistas, historiadores e literatos. Dentre os reveses futebolísticos brasileiros, poucos são tão lembrados como o que ficou conhecido por Tragédia do Sarriá, nome dado à derrota para a seleção italiana, em 05 de julho de 1982, que eliminou a seleção brasileira da Copa do Mundo. ${ }^{1}$

Assim como o amplo acervo de materiais produzidos sobre a Tragédia do Sarriá, ${ }^{2}$ chama atenção a convergência de grande parte destes conteúdos no sentido de tentar explicar, mesmo décadas após o ocorrido, os motivos que levaram a seleção brasileira de 1982 a não ser campeã. Livros que foram publicados no país desde o início deste século oferecem contornos mais delimitados a essa ideia, caso, por exemplo, da obra Sarriá 82: o que faltou ao futebol-arte? (2012), cujo subtítulo já aponta o caráter pretensamente explicativo da obra. Para Lédio Carmona, que escreve a contracapa do livro, "quanto mais o tempo passa, novas teorias surgem para explicar por que aquela fantástica seleção brasileira perdeu a Copa. Qual é o enigma da Tragédia do Sarriá? 0 ótimo livro dos amigos Gustavo Roman e Renato Zanata Arnos é a esperança diante desse mantra interrogativo". ${ }^{3}$ Mauro Cezar Pereira, responsável pela orelha do livro, destaca que os autores assistiram às partidas da seleção brasileira de 1982 e entrevistaram

\footnotetext{
${ }^{1} \mathrm{Na}$ Copa do Mundo de 1982, sediada na Espanha, a seleção brasileira venceu as três partidas disputadas na primeira fase, contra as seleções da União Soviética $(2 \times 1)$, da Escócia $(4 \times 1)$ e da Nova Zelândia $(4 \times 0)$. Na segunda fase, após mais um triunfo, contra a seleção da Argentina $(3 \times 1)$, a seleção brasileira precisava apenas de uma empate diante da seleção italiana para avançar à fase semifinal, porém acabou derrotada por $3 \times 2$ no Estádio de Sarriá, em Barcelona, e terminou o Mundial na quinta colocação.

${ }^{2}$ Apenas a título de ilustração, é válido mencionar que, em se tratando de materiais sobre as participações brasileiras em Copas do Mundo, uma busca realizada em livrarias virtuais aponta que a quantidade de obras relacionadas à seleção brasileira de 1982 é igualada apenas pelo número de livros sobre a seleção brasileira de 1950. A Copa do Mundo de 1950 foi sediada no Brasil e a seleção brasileira chegou ao último jogo do torneio podendo até empatar com a seleção uruguaia para se consagrar campeã, mas perdeu a partida no Estádio do Maracanã por 2 × 1, revés que ficou conhecido como "Maracanazo".

${ }^{3}$ CARMONA. Sarriá 82: o que faltou ao futebol-arte?, contracapa.
} 
participantes daquela equipe buscando responder a seguinte pergunta: "O que explica os 3 a 2 protagonizados por Paolo Rossi?". ${ }^{4}$ Prosseguindo, Pereira afirma que quem ler o livro "entenderá por que a seleção de Telê estava longe da perfeição. Conhecerá seus defeitos, vulnerabilidades, pontos fracos explorados pela Itália em 1982".

Um dos futebolistas mais celebrados da seleção brasileira de 1982, Paulo Roberto Falcão, autor do livro Brasil 82: o time que perdeu a Copa e conquistou o mundo (2012), deixa claro, ao traçar os objetivos de sua obra, o intuito de elucidar as causas da Tragédia do Sarriá:

Durante 30 anos ouvi elogios para o que fizemos na Espanha, conjugados com manifestações de solidariedade e com uma pergunta insistente: por que perdemos? Este livro, baseado numa vida inteira de dedicação ao futebol e no depoimento dos participantes daquela epopeia, tenta respondê-la. ${ }^{6}$

Diante de tal objetivo, o terceiro capítulo do livro, intitulado "Por que perdemos?", apresenta relatos de 11 jogadores brasileiros que participaram do Mundial de 1982. Abrindo as narrativas, Falcão reforça a busca por explicações: "Trinta anos depois, eles estão respondendo a pergunta que não calou um só dia desse período: por que perdemos?". ${ }^{7}$

A procura por motivos para a não conquista do que seria, então, o quarto título mundial da seleção brasileira também é a tônica de outros livros. Em Telê e a seleção de 82: da arte à tragédia (2012), Luís Simon realiza as seguintes perguntas e promessa ao apresentar a obra: "Mas por que a seleção de 1982, eliminada nas quartas de final? [...] Quer saber? Leia o livro do Marcelo Mora. Você vai entender tudo". ${ }^{8}$ Em A falta que faz um gol (2002), Jeferson de Andrade pesquisa materiais jornalísticos à época publicados para narrar o que confia ser uma versão desconhecida da Tragédia do Sarriá. Daí o subtítulo do livro ser “Copa de 1982: o outro lado de uma derrota" e a chamada ser feita nestes termos:

\footnotetext{
${ }^{4}$ PEREIRA. Sarriá 82, orelha do livro.

${ }^{5}$ PEREIRA. Sarriá 82, orelha do livro.

${ }^{6}$ FALCÃO. Brasil 82, p. 11.

7 FALCÃO. Brasil 82, p. 12.

${ }^{8}$ SIMON. Telê e a seleção de 82 , orelha do livro.
} 
[...] se você acompanha futebol e se lembra da derrota do Brasil para a Itália na Copa do Mundo de 1982, se você não se lembra, mas conhece algumas histórias daquele jogo, abra este livro e terá uma das maiores surpresas de sua vida com revelações inéditas do escritor Jeferson de Andrade. ${ }^{9}$

Personagem dos mais marcantes do futebol brasileiro, João Saldanha foi colunista do Jornal do Brasil durante os anos 1980. Décadas depois, seus textos relacionados à Copa do Mundo de 1982 foram republicados na coletânea $O$ trauma da bola: a Copa de 82 por João Saldanha (2002). A partir da forma como Ruy Castro apresenta a coletânea é possível interpretar que, também nela, há a pretensão de se explicar o revés frente à seleção da Itália:

Mas, na Espanha, mesmo durante as vitórias, um homem não se cansara de denunciar os erros da preparação, as teimosias do treinador e a possibilidade de uma decepção: João Saldanha. Vinte anos depois, a coleção Zona do Agrião estréia resgatando os artigos de Saldanha, que formam um fascinante e revelador diário sobre uma Copa que o Brasil jamais conseguirá esquecer. ${ }^{10}$

Erros técnicos individuais, escolhas táticas equivocadas, imprevisibilidades características do futebol, falta de humildade... Essas são apenas algumas das muitas justificativas para a derrota de 1982 que são encontradas nos depoimentos dos jogadores dados a Falcão (2012). Roman e Zanata (2012) ancoram-se em análises táticas e apontam erros cometidos pela seleção brasileira de 1982, chegando ao ponto de sugerirem estratégias diferentes das então escolhidas pelo treinador Telê Santana. Por sua vez, Andrade (2002) baseia-se em materiais jornalísticos e descrições minuciosasdos jogos da seleção brasileira de 1982 para argumentar que a derrota se deu porque Falcão não queria passar a bola para Zico durante as partidas. Já João Saldanha (2002) não se limita a um único motivo, culpando desde a preparação física excessivamente intensa no período pré-torneio até a teimosia de Telê Santana, passando pela falta de modéstia dos jogadores. É justamente essa diversidade e abrangência dos argumentos que buscam descortinar

\footnotetext{
${ }^{9}$ ANDRADE. A falta que faz um gol, contracapa.

${ }^{10}$ CASTRO. O trauma da bola, contracapa.
} 
a Tragédia do Sarriá que leva Mora (2012), ao final de seu livro, a concluir que "a busca por explicações ocorre até os dias de hoje. Em vão, claro". ${ }^{11}$

0 presente artigo pretende entender porque a Tragédia do Sarriá, mesmo após décadas, coloca-se como uma das passagens mais relembradas da história do futebol brasileiro e que mais demanda explicações. Diante da multiplicidade de formas de se olhar para tal questão, este trabalho objetiva analisar a construção de representações sobre o estilo de jogo da seleção brasileira de 1982, o chamado futebol-arte, em livros publicados no século XXI que se dedicam a narrara trajetória desta equipe. Com a promessa de apresentar as devidas justificativas teóricas ao longo do texto, o foco da análise será direcionado para os contextos de comparação entre as seleções brasileiras de 1982 e de 1994, dado que esta última surge como um significativo ponto de contraste na produção de representações sobre a primeira. Dito isso, a etapa inicial a ser realizada na busca dos objetivos propostos consiste em elaborar o que se entende, aqui, por "estilo de jogo" e "representações sociais", tarefa à qual se dedica a próxima seção.

No mínimo desde a publicação de Universo do Futebol - Esporte e Sociedade Brasileira (1982), muito já se discutiu na Antropologia dos Esportes acerca da participação do futebol, no Brasil, na produção e difusão de símbolos e identidades nacionais. Partindo desse pressuposto, acredita-se que tal espaço ocupado pelo futebol é fruto de um complexo processo em vigência desde no mínimo os anos 1930 e que envolve uma relação na qual a seleção brasileira surge como metáfora da nação. Refletindo sobre os mecanismos desse processo, Guedes propõe a noção de estilo de jogo como um operador simbólico capaz de promover o "trânsito entre as representações próprias ao campo desportivo e aquelas referentes à produção das especificidades nacionais", 12 possibilitando interpretar os desempenhos dos jogadores

\footnotetext{
${ }^{11}$ MORA. Telê e a seleção de 82, p. 116.

${ }^{12}$ GUEDES. A produção das diferenças na produção dos "estilos de jogo" no futebol, p. 156-157.
} 
brasileiros nos gramados como representativos da forma de viver dos brasileiros. Em suma, "estabelece-se uma conexão entre 'estilo de jogo' e 'estilo de vida"'. ${ }^{13}$

Pensando a produção de estilos de jogo, Guedes observa que um estilo de jogo não se realiza ao longo de todo o desempenho de uma equipe, mas apenas em alguns momentos que acabam "eternizados em narrativas, textos, fotos e, mais recentemente, em vídeos e filmes que selecionam e recortam o que é significativo e relevante para confirmar e reificar estas representações". ${ }^{14}$ Recuperando o postulado da Escola Sociológica Francesa de que as "representações coletivas [...] não são 'reflexo' dos 'verdadeiros' fenômenos sociais: elas são parte fundamental destes fenômenos", ${ }^{15}$ a construção dos estilos de jogo é vista como processos em que "representações e práticas sociais são parte do mesmo fenômeno social em permanente negociação". ${ }^{16}$ Assim, os estilos de jogo jamais podem ser tomados como meras descrições de uma prática que já estava definida a priori. Pelo contrário, um estilo de jogo é resultado de um complexo processo de construção social em que

[...] as representações coletivas desempenham um papel fundamental: selecionando pelo aplauso ou pelo apupo os desempenhos valorizados, estimulando os usos sociais do corpo escolhidos, destacando e recompensando os indivíduos que melhor representam os valores selecionados. ${ }^{17}$

Seguindo a orientação de que pensar estilos de jogar futebol é caminhar pela estrada da produção e do compartilhamento de representações, acredita-se que os argumentos desenvolvidos por Serge Moscovici ao elaborar a teoria das representações sociais têm muito a acrescentar à discussão sobre a construção social do estilo de jogo brasileiro.

Uma forma inicial de tatear a teoria das representações sociais é pensá-la como um afastamento em relação à perspectiva que vê os fenômenos psicossociais como centrados no indivíduo. Para Moscovici, essa perspectiva a ser negada se expressa em três argumentos. 0 primeiro é o de que "alguém atinge os verdadeiros

\footnotetext{
${ }^{13}$ GUEDES. A produção das diferenças na produção dos "estilos de jogo" no futebol, p. 157.

${ }^{14}$ GUEDES. A produção das diferenças na produção dos "estilos de jogo" no futebol, p. 158.

${ }^{15}$ GUEDES. A produção das diferenças na produção dos "estilos de jogo" no futebol, p. 160.

${ }^{16}$ GUEDES. A produção das diferenças na produção dos "estilos de jogo" no futebol, p. 158.

17 GUEDES. De criollos e capoeiras, p. 137.
} 
processos do conhecimento quando esses processos são pensados dentro do indivíduo, independentemente de sua cultura e, concretamente, de qualquer cultura". ${ }^{18} \mathrm{O}$ segundo, o de que "as pessoas se comportam de maneira correta e racional quando sozinhas, mas tornam-se imorais e irracionais quando agem em grupo". ${ }^{19}$ Por fim, a ideia de que os processos cognitivos associados aos fenômenos individuais, por serem mais elementares, seriam regidos por leis que servem de referência para os fenômenos sociais.

Para se distanciar daquilo que classifica como uma "psicologia individual", 20 Moscovici recorre à noção de representações coletivas, desenvolvida por Durkheim, tornando tal distanciamento uma simultâneaaproximação a pressupostos que, sob a ótica da relação indivíduo-sociedade, valorizam o segundo termo da expressão na interpretação dos fenômenos psicossociais. Por isso, não há exagero na afirmação de que o modo de Moscovici enxergar as percepções individuais como produtos sociais floresce do contato com ideias durkheimianas, como se percebe na maneira de: a) pensar a sociedade como mais do que uma simples reunião de indivíduos com interesses mútuos; b) sugerir que atos experimentados pelos indivíduos na vida social aparecem como incoerentes se tomados como frutos exclusivos de expressões individuais; c) defender a racionalidade das concepções coletivas justamente por serem de origem coletiva, negando a ideia de que razão e sociedade são antitéticas; d) notar o impacto das formas coletivas de pensamento nos modos de agir e sentir dos indivíduos; e) afirmar a impossibilidade de se compreender o conhecimento partilhado por indivíduos de uma mesma sociedade a partir de leis baseadas em experiências sensoriais individuais. Assim, nas precisas palavras de Robert Farr: "Existe uma clara continuidade entre o estudo das representações coletivas de Durkheim e o estudo mais moderno, de Moscovici, sobre representações sociais". ${ }^{21}$

Se um primeiro movimento tomado por Moscovici na criação da teoria das representações sociais foi de aproximação à tese durkheimiana, o movimento seguinte é o de relativizar alguns fundamentos da noção de representação coletiva,

\footnotetext{
${ }^{18} \mathrm{MOSCOVICI}$. A história e a atualidade das representações sociais, p. 170.

${ }^{19} \mathrm{MOSCOVICl}$. A história e a atualidade das representações sociais, p. 170.

${ }^{20} \mathrm{MOSCOVICI}$. A história e a atualidade das representações sociais, p. 181.

${ }^{21}$ FARR. Representações sociais, p. 32.
} 
como se torna explícito nesta polida justificativa: "Ao falar de representações sociais em lugar de representações coletivas, quis romper com as associações que o termo coletivo tinha herdado do passado e também com as interpretações sociológicas e psicológicas que determinaram sua natureza no procedimento clássico". ${ }^{22}$ Embora o diálogo teórico com Durkheim tenha contribuído para Moscovici perceber o quanto de social há no individual, isso não o fez colocar uma barreira a separando indivíduo e sociedade. Ultrapassando as perspectivas que enxergam a relação indivíduo-sociedade como uma antítese, não raro argumentando em prol da dominância de um dos polos sobre o outro, percebe-se em Moscovici tanto a aproximação a ideias que negam que "todos os comportamentos e todas as percepções são compreendidos como resultantes de processos íntimos, às vezes de natureza fisiológica", ${ }^{23}$ como a opção por não reproduzir ipsis litteris a noção durkheimiana de representação coletiva, já que fazê-lo seria "uma redução inversa, negando a especificidade do indivíduo e fazendo do consenso o resultado de uma interação que faça desaparecer as distinções entre os indivíduos". ${ }^{24}$

Destarte, o eixo central da teoria das representações sociais é a comunicação, sendo que as representações nem são produzidas por indivíduos isolados com base em percepções sensoriais, nem são internalizadas de forma inerte pelo indivíduo devido a um absoluto poder de coerção exercido pela sociedade, mas sim construídas "através de influências recíprocas, através de negociações implícitas no curso das conversações, onde as pessoas se orientam para modelos simbólicos, imagens e valores compartilhados específicos". Daí a definição de representações sociais como representações compartilhadas [...]. Muitas vezes me perguntaram o que quero dizer com partilhar uma representação ou por representações compartilhadas. 0 que lhes dá esse caráter não é o fato de elas serem autônomas, ou que elas sejam comuns, mas sim o fato de seus elementos terem sido construídos através da comunicação e estarem relacionados pela comunicação. ${ }^{25}$

Além do caráter comunicativo e da origem compartilhada, as representações sociais são definidas pela natureza fluida. Uma representação social consiste em

\footnotetext{
${ }^{22} \mathrm{MOSCOVICI}$. A história e a atualidade das representações sociais, p. 198.

${ }^{23} \mathrm{MOSCOVICl}$. Prefácio, p.11

${ }^{24}$ MOSCOVICl. Prefácio, p.12.

${ }^{25} \mathrm{MOSCOVICI}$. A história e a atualidade das representações sociais, p. 208-209.
} 
um "modelo recorrente e compreensivo de imagens, crenças e comportamentos simbólicos" ${ }^{26}$ que permite que as pessoas classifiquem, descrevam e expliquem elementos da vida social. Moscovici rechaça ideias que enxerguem o conteúdo desses modelos como reflexos imutáveis de uma realidade definida a priori, afirmando que os conteúdos das representações sociais variam de uma sociedade a outra e, também, dentro de um mesmo grupo, sendo que "os contextos da comunicação em que essas representações são elaboradas, são responsáveis por essas diferenças". ${ }^{27}$ Assim, tem-se que as representações sociais definem-se como construções contextuais que envolvem tanto a agência dos indivíduos que a partilham como a cultura a que eles pertencem. Nos termos de Moscovici:

[...] as categorias e sentidos através dos quais nós "escolhemos" conferir uma característica às pessoas, ou propriedades aos objetos, se modificam. Como exemplos, nós "escolhemos" descrever um alimento pelo seu gosto ou pelo seu valor proteico, de acordo com a cultura à qual pertencemos ou pelo uso que nós queremos fazer dele. Torna-se impossível exigir que todas essas qualidades sejam reduzidas a uma única qualidade "verdadeira". Isso implicaria que exista uma realidade dada, totalmente acabada, para esse alimento, que é imposta a nós independentemente da representação que nós compartilhamos. ${ }^{28}$

Tratando o estilo de jogo como um operador simbólico capaz de promover o fluxo de mão dupla entre representações relacionadas ao que os jogadores fazem em campo e representações referentes à produção de singularidades nacionais, epensando a construção social de um estilo de jogo como um fenômeno complexo, dinâmico e contextual, em que representações e práticas não podem ser pensadas isoladamente, as próximas elaborações discutem a categoria "futebol-arte" e sua relação com a seleção brasileira de 1982. Confia-se que os objetivos aqui propostos serão pensados de modo mais consistente após uma prévia argumentação sobre como a seleção brasileira de 1982 tem sido construída como símbolo do futebolarte desde as primeiras representações produzidas e difundidas a seu respeito.

\footnotetext{
${ }^{26} \mathrm{MOSCOVICI}$. A história e a atualidade das representações sociais, p. 209.

${ }^{27} \mathrm{MOSCOVICl}$. A história e a atualidade das representações sociais, p. 213.

${ }^{28} \mathrm{MOSCOVICl}$. A história e a atualidade das representações sociais, p. 212.
} 


\section{II}

Fazendo a pertinente ressalva de que representações sociais e categorias não possuem certidão de nascimento, concorda-se que Gilberto Freyre é um dos agentes responsáveis por “'inventar', do ponto de vista sociológico, a própria idéia de futebol-arte", 29 e que o artigo de sua autoria intitulado "Foot-Ball mulato" (1938) é "uma das primeiras e mais influentes construções do que viria a ser conhecido como 'futebol-arte' brasileiro". ${ }^{30}$

Ao longo da década de 1920 viu-se a emergência gradativa de uma nova perspectiva de definição do brasileiro, perspectiva esta que contestava a "negação da existência de uma identidade brasileira porque a civilização que a sustentava era heterogênea", ${ }^{31}$ sugerindo, em seu lugar, "a admissão da existência dessa identidade justamente porque esta civilização era sincrética". ${ }^{32}$ Nesse cenário, Gilberto Freyre, principalmente após a publicação, em 1933, de Casa-grande \& senzala, posiciona-se como um dos mais proeminentes intelectuais que então argumentavam a favor da tese de que a riqueza da cultura nacional se encontrava nas fontes diversas que originavam seus elementos: os portugueses, os negros e os índios.

Explicitando o desejo por separar raça e cultura, ou, em outros termos, o genético do social, Freyre, através da paulatina adoção de uma perspectiva culturalista, compreende a formação do brasileiro como um "processo de equilíbrio de antagonismos", 33 no sentido de nele se verificar "o encontro, a intercomunicação e até a fusão harmoniosa de tradições diversas, ou antes, antagônicas, de cultura". ${ }^{44}$ Ao amortecer os conflitos e harmonizar os antagonismos presentes na formação do brasileiro como "o tipo ideal do homem moderno para os trópicos, europeu com sangue negro ou índio a avivar-lhe a energia", 35 a mestiçagem é elevada por Freyre ao posto de maior símbolo da cultura brasileira.

\footnotetext{
${ }^{29}$ VELHO BARRETO. Gilberto Freyre e o Futebol-Arte, p. 234.

${ }^{30}$ GUEDES. A produção das diferenças na produção dos "estilos de jogo" no futebol, p. 154.

${ }^{31}$ QUEIROZ. Identidade Nacional, Religião, Expressões Culturais, p. 73.

32 QUEIROZ. Identidade Nacional, Religião, Expressões Culturais, p. 73.

${ }^{33}$ FREYRE. Casa-grande \& senzala, p. 116.

${ }^{34}$ FREYRE. Casa-grande \& senzala, p. 115.

${ }^{35}$ FREYRE. Casa-grande \& senzala, p. 110.
} 
Para Freyre, a mestiçagem se fazia presente em todas as expressões culturais definidas como "verdadeiramente" brasileiras, e não haveria porque ser diferente com o futebol praticado no Brasil nos anos 1930, que se encontrava em processo de massificação, popularização e já repleto de jogadores negros e mulatos ao lado dos brancos, que antes eram maioria quase absoluta. Ocorre que, para assumir o futebol como um demonstrativo empírico da mestiçagem, logo, da brasilidade, Freyre necessitou de uma construção simbólica que fosse capaz de convergir as representações do que os jogadores faziam em campo com as representações relacionadas ao que os brasileiros faziam fora dele. Como tem sido aqui proposto, essa construção simbólica é justamente o estilo de jogo brasileiro.

Dado que os processos de produção de identidades precisam "construir ao mesmo tempo o 'nós' e o 'outro', ou seja, para produzir a identidade é necessário produzir alteridades relacionais e contrastivas", ${ }^{36}$ no mesmo movimento que tencionava pôr em evidência o que considerava o estilo de jogo brasileiro, Freyre precisou criarum estilo de jogo contrastante. Nesse processo, foram principalmente os ingleses, difusores das metodologias dominantes nos primeiros anos de prática do futebol no Brasil, ainda no século XIX, que serviram a Freyre como alteridades relacionais no movimento de construção da identidade nacional brasileira a partir de um estilo de jogo próprio. Na elaboração freyriana, o estilo de jogo brasileiro foi categorizado como dionisíaco, enquanto o estilo de jogo inglês/europeu acabou definido como apolíneo.

Sempre em tom contrastivo, tomando como alteridade o europeu ou, mais particularmente, o inglês, Freyre expõe, ao longo de "Foot-Ball mulato" (1938), características do modo de jogar brasileiro, propondo que o "estylo mulato, afrobrasileiro, de foot-ball é uma forma de dansa dyonisíaca". ${ }^{37}$ Assim, para o autor, "os europeus teem procurado eliminar quasi todo o floreio artístico, quasi toda a variação individual, quasi toda a espontaneidade pessoal para accentuar a belleza dos effeitos geométricos e a pureza de technica scientífica", ${ }^{38}$ enquanto o estilo brasileiro - "Inimigo do formalismo apolíneo e amigo das variações" ${ }^{39}$ -

\footnotetext{
${ }^{36}$ GUEDES. A produção das diferenças na produção dos "estilos de jogo" no futebol, p. 163-164.

${ }^{37}$ FREYRE. Foot-ball mulato, $s / n$.

${ }^{38}$ FREYRE. Foot-ball mulato, $\mathrm{s} / \mathrm{n}$.

${ }^{39}$ FREYRE. Foot-ball mulato, $\mathrm{s} / \mathrm{n}$.
} 
caracteriza-se por ser: "Rebelde a excessos de ordenação interna e externa; a excessos de uniformisação de geometrisação, de standartização; a totalitarismos que façam desapparecer a variação individual ou espontaneidade pessoal" ${ }^{40}$

Embora sucinta, a contextualização dos pressupostos freyrianos sobre o estilo de jogo brasileiro é fundamental para a argumentação de que a seleção brasileira de 1982 tem sido socialmente construída como símbolo do futebol-arte desde seus primeiros momentos nos gramados, visto que, como sugere um estudo sobre os textos escritos por Nelson Motta durante o Mundial de 1982: "Durante a Copa do Mundo da Espanha, pôde-se notar, não apenas nas crônicas de Nelson Motta, mas na maioria dos periódicos especializados ou não em futebol, um discurso que retomava as teorias de Gilberto Freyre, em especial a veiculada na obra Casa-grande e senzala" ${ }^{41}$ Seguindo o raciocínio, as próximas linhas discutem algumas conclusões alcançadas por três artigos recentemente publicados que analisam a produção de representações sobre a seleção brasileira de 1982 concomitantemente ao desenrolar da Copa do Mundo daquele ano.

0 artigo "1982: lágrimas de uma geração de ouro" (2014) compara conteúdos produzidos pela imprensa acerca das derrotas sofridas pelas seleções brasileiras de 1950 e 1982 e argumenta que se em 1950 as lágrimas pela derrota em pleno Maracanã "se relacionavam à decepção e à suspeita de que o Brasil havia perdido uma oportunidade ímpar de provar ao mundo e a si mesmo que era capaz de grandes realizações e conquistas", ${ }^{42}$ em 1982 a tristeza foi representada de outra maneira: "As lágrimas de 1982 tiveram um significado diferente. Chorou-se com a seleção lamentando-se um infortúnio que sobre ela se abateu, infortúnio que condenava uma geração de ouro, talentosa e considerada merecedora das glórias do futebol" ${ }^{43}$ Segundo a autora, ao invés de se encontrar uma busca por culpados nos materiais que tentavam explicar a Tragédia do Sarriá, como era comum nos períodos que se seguiam a eliminações brasileiras em Copas do Mundo, o que se viu foi um sentimento de compaixão para com a seleção brasileira de 1982. Costa enxerga que a eliminação para a seleção italiana ganhou contornos de uma

\footnotetext{
${ }^{40}$ FREYRE. Foot-ball mulato, s/n.

${ }^{41}$ LISE et al. A Copa do Mundo de 1982 e o "turbilhão de emoções" nas crônicas de Nelson Motta, p. 13.

42 COSTA. 1982: lágrimas de uma geração de ouro, p. 166.

${ }^{43}$ COSTA. 1982: lágrimas de uma geração de ouro, p. 167.
} 
injustiça digna de compaixão porque a seleção brasileira de 1982, já naquele momento, era representada como uma equipe que "demonstrava um futebol por muitos considerado um autêntico representante do futebol-arte", ${ }^{44}$ tanto porque contava com “uma 'geração de ouro', que reunia jogadores como Sócrates, Júnior, Falcão e Zico, vencedores em seus clubes e reconhecidos pela grande habilidade com a bola", ${ }^{45}$ como porque "jogava um futebol vistoso e estimulava o otimismo" ${ }^{46}$ Ainda acerca dos processos de construção da derrota na Copa do Mundo de 1982 como uma tragédia e de produção de representações sobre o estilo de jogopraticado pela seleção de 1982:

Assim, é válido ressaltar que não foi apenas o desempenho em campo o fator responsável por tamanha expectativa e posterior decepção. Havia um aparato discursivo que colocava em circulação uma série de representações e significados que iam sendo anexados àquela seleção. Representações relacionadas ao futebol-arte, tão caro à imagem e à autoimagem do futebol brasileiro. A seleção de 1982 foi compreendida por muitos como aquela que traria de volta um futebol especial. ${ }^{47}$

A conclusão de que a tristeza pela derrota e o orgulho por recuperar a identidade perdida se misturam na Tragédia do Sarriá também é apresentada no artigo "Jornal da Tarde, 6 de julho de 1982: a imagem como construção de sentidos de uma derrota" (2016), trabalho que analisa o processo de produção de sentidos associado à foto de autoria de Reginaldo Manente, que ilustrou a capa da edição do Jornal da Tarde, publicada no dia seguinte à eliminação da seleção brasileira na Copa do Mundo de 1982. Investigando conteúdos midiáticos produzidos durante a Copa do Mundo de 1982 para compreender o contexto de então, os autores afirmam que enquanto as "derrotas nas Copas de 1974 e 1978 foram narradas pela imprensa como fugas de 'nossa essência', por conta do estilo de futebol classificado como 'futebol-força'”, ${ }^{48}$ a forma de jogar futebol da seleção brasileira de 1982 nos gramados espanhóis "foi considerada pela mídia um retorno às 'raízes

\footnotetext{
${ }^{44}$ COSTA. 1982: lágrimas de uma geração de ouro, p. 177.

${ }^{45}$ COSTA. 1982: lágrimas de uma geração de ouro, p. 177.

${ }^{46}$ COSTA. 1982: lágrimas de uma geração de ouro, p. 177.

${ }^{47}$ COSTA. 1982: lágrimas de uma geração de ouro, p. 180.

48 MOSTARO; HELAL. Jornal da Tarde, 6 de julho de 1982: a imagem como construção de sentidos de uma derrota, p. 21.
} 
nacionais'”. ${ }^{49}$ Daí, o surgimento, ao longo do torneio, de um sentimento de euforia nos torcedores por verem a seleção confirmar a identidade brasileira ao praticar um futebol "baseado no drible, improviso, ofensividade e floreios com a bola", 50 sentimento este que não se apagou nem mesmo com a eliminação, como simbolizaria a ilustração de capa do Jornal da Tarde. Para Mostaro e Helal, a imagem de um menino tentando conter o choro enquanto mantém a pose com o peito erguido simboliza ao mesmo tempo a tristeza pelo fim da chance de conquistar o título e o orgulho de quem caiu honrando a tradição: "a 'dor nacional' pela derrota, mas com o 'peito estufado' por praticar o 'nosso estilo' teve como ícone a fotografia analisada". 51

Também constituindo seu objeto de pesquisa com materiais produzidos e veiculados pela mídia impressa, o artigo "A Copa do Mundo de 1982 e o "turbilhão de emoções" nas crônicas de Nelson Motta" (2017) se dedica a analisar os escritos de Nelson Motta para o jornal O Globo durante a Copa do Mundo de 1982 "a fim de perceber quais eram as impressões/concepções do jornalista acerca da Copa do Mundo, bem como da equipe brasileira que disputou tal campeonato". ${ }^{52}$ Segundo os autores, as crônicas de Nelson Motta permitem interpretar que a seleção brasileira de 1982 "representava uma retomada da identidade brasileira, baseada no jogo bonito, criativo, de gingado típico dos trópicos", 53 dado que as seleções brasileiras que tinham disputado as Copas do Mundo de 1974 e 1978 haviam praticado "um futebol parecido com o estilo europeu de jogar, menos ofensivo, menos criativo, pautado principalmente pela marcação e pouca ofensividade". ${ }^{54}$ Prosseguindo com a análise, os autores argumentam: “Após a longa espera de 12 anos a seleção brasileira de 1982 recuperava aquela índole ofensiva de 1970. As atuações da equipe nacional eram convincentes, o futebol nacional voltava a ser

\footnotetext{
${ }^{49}$ MOSTARO; HELAL. Jornal da Tarde, 6 de julho de 1982: a imagem como construção de sentidos de uma derrota, p. 21-22.

${ }_{50}$ MOSTARO; HELAL. Jornal da Tarde, 6 de julho de 1982: a imagem como construção de sentidos de uma derrota, p. 21.

${ }^{51}$ MOSTARO; HELAL. Jornal da Tarde, 6 de julho de 1982: a imagem como construção de sentidos de uma derrota, p. 34.

${ }_{52}$ LISE et al. A Copa do Mundo de 1982 e o "turbilhão de emoções" nas crônicas de Nelson Motta, p. 12.

53 LISE et al. A Copa do Mundo de 1982 e o "turbilhão de emoções" nas crônicas de Nelson Motta, p. 15.

${ }^{54}$ LISE et al. A Copa do Mundo de 1982 e o "turbilhão de emoções" nas crônicas de Nelson Motta, p. 14.
} 
jogado de um 'jeito tipicamente brasileiro'", 55 Ainda acerca das impressões de Nelson Motta sobre a seleção brasileira de 1982, os autores sugerem a reprodução e o reforço da ideia "de que o futebol-arte brasileiro é o melhor futebol do mundo", ${ }^{56}$ de modo que um resultado negativo não seria capaz de apagar a admiração em relação à forma de jogar tipicamente brasileira.

Embora Costa (2014), Mostraro e Helal (2016) e Lise et al (2017) apresentem objetivos e discussões teórico-metodológicas diferentes, os três estudos, ao analisarem conteúdos simbólicos produzidos no período de atuação da seleção brasileira de 1982, elaboram algumas argumentações convergentes. Para o intuito deste artigo, a conclusão mais relevante alcançada pelos trabalhos em questão é a de que, nos produtos jornalísticos, encontrava-se a narrativa de que, após as edições de 1974 e 1978 da Copa do Mundo, quando os representantes brasileiros teriam abandonado sua "essência" futebolística e praticado otipicamente europeu futebol-força, a seleção brasileira de 1982 surgiu como símbolo da retomada do "genuinamente" brasileiro futebol-arte. Aprofundando esse argumento, LISE et al (2017) ainda sugere a hipótese de que a crença no retorno às suas "raízes futebolísticas", promovido pela seleção brasileira de 1982, motivou uma retomada dos pressupostos elaborados por Gilberto Freyre sobre o estilo de jogo brasileiro por parte do discurso jornalístico, hipótese esta que, acredita-se, também encontra sustentação nas análises de Costa (2014) e Mostaro e Helal (2016). Acerca da presença de ideias freyrianas no processo de produção de representações sobre a seleção brasileira de 1982, os autores afirmam:

[...] parte-se, aqui, da hipótese de que esse retorno à tese sociológica freyriana teria um motivo principal. Após a Copa do Mundo no México, em 1970, na qual o Brasil se sagrou tricampeão mundial, a seleção brasileira jamais reapresentou um futebol sequer razoável. Nas Copas de 1974 e 1978 o futebol-arte cedeu lugar a um "futebol-força". ${ }^{57}$

Por óbvias razões cronológicas, a construção da seleção brasileira de 1982 como símbolo do futebol-arte durante seu período de atuação nos gramados

\footnotetext{
${ }^{55}$ LISE et al. A Copa do Mundo de 1982 e o "turbilhão de emoções" nas crônicas de Nelson Motta, p. 14.

56 LISE et al. A Copa do Mundo de 1982 e o "turbilhão de emoções" nas crônicas de Nelson Motta, p. 15.

${ }^{57}$ LISE et al. A Copa do Mundo de 1982 e o "turbilhão de emoções" nas crônicas de Nelson Motta, p. 14.
} 
apresentou como alteridades equipes então contemporâneas, como a própria seleção italiana de 1982 que a derrotou na Copa, ou equipes do passado, caso destacado das seleções brasileiras de 1974 e 1978. Atualmente, transcorridos quase 40 anos da Tragédia do Sarriá, embora a produção de representações sobre a seleção brasileira de 1982 como praticante do futebol-arte ainda esteja fortemente em evidência em diversas esferas, verifica-se que novas alteridades passaram a ocupar espaços de destaque neste processo. Dentre essas novas alteridades, nenhuma é tão significativa quanto a seleção brasileira de 1994.

\section{III}

De acordo com Soares e Lovisolo (2013), a comparação com a forma de jogar dos ingleses faz parte da construção de representações sobre o modo de jogar dos brasileiros desde o início do século XX. Inclusive, como se mencionou linhas acima, as comparações com ingleses, em particular, e europeus, em geral, são os pilares das ideias elaboradas por Gilberto Freyre que definem o estilo de jogo brasileiro como dionisíaco, em oposição ao estilo de jogo apolíneo dos europeus. Há de se ressaltar ainda o desenvolvido por Guedes (2006) acerca da relevância adquirida nas últimas décadas pelo estilo de jogo argentino como alteridade na construção do futebol-arte.

Entretanto, ao se analisar livros publicados neste século centrados em narrar a trajetória da seleção brasileira de 1982, a posição de alteridade privilegiada no processo de produção de representações sobre esta seleção não é ocupada nem por times ingleses, nem por equipes argentinas, nem pela algoz seleção italiana que venceu o Mundial de 1982 e nem mesmo pelas seleções brasileiras de 1974 e 1978, mas sim pela seleção brasileira campeã da Copa do Mundo de $1994 .^{58}$ Salta aos olhos a frequência das comparações entre as seleções brasileiras de 1982 e de 1994 e, não raramente, essas comparações envolvem a

\footnotetext{
${ }^{58}$ A seleção brasileira conquistou a Copa do Mundo de 1994, realizada nos Estados Unidos, depois de 24 anos sem levantar a taça. Na primeira fase da campanha, a equipe venceu as seleções da Rússia $(2 \times 0)$ e do Camarões $(3 \times 0)$, empatando em seguida com a seleção sueca $(1 \times 1)$. Nos jogos seguintes, todos eles eliminatórios, a seleção brasileira venceu a norte-americana $(1 \times 0)$, a holandesa $(3 \times 2)$, a sueca $(1 \times 0)$ e, na partida final, contra a seleção italiana, ganhou na disputa de pênaltis por $3 \times 2$ após um empate sem gols. A conquista nos Estados Unidos foi a quarta da história da seleção brasileira nas Copas do Mundo.
} 
complexa questão sobre se é melhor vencer uma Copa do Mundo jogando como em 1994 ou perder como em 1982, pergunta esta que, só por ser enunciada recorrentemente, independente da resposta, já rascunha os primeiros contornos da análise que se segue. ${ }^{59}$

Tão significativa quanto a questão anterior é a explicitação do desejo de se trocar o título conquistado na Copa do Mundo de 1994 pelo perdido na de 1982. Mesmo que o livro É tetra: a conquista que ajudou a mudar o Brasil (2014), um dos raros a narrar a campanha da seleção brasileira de 1994, não faça parte do objeto de pesquisa deste artigo, é de grande valia citar as emblemáticas primeiras linhas escritas por Mauro Beting no prefácio:

Eu trocaria o gol que o Brasil não fez na Itália em 120 minutos de calor em Passadena em 1994 pelo pesadelo de ter feito um gol a menos que Paolo Rossi em Sarriá, em 1982. Revejo com prazer até mesmo a derrota do Brasil de Telê e do mundo da bola na Copa da Espanha. Revejo com algum pesar muitos dos jogos do Brasil de Parreira tetracampeão nos Estados Unidos. ${ }^{60}$

Um contexto no qual as comparações entre as seleções brasileiras de 1982 e de 1994 se sobressaem é aquele em que se exalta a herança deixada pela seleção de 1982. Argumentando sobre o legado da seleção brasileira de 1982, Roman e Zanata (2012) apresentam discursos que afirmam a injustiça da derrota para a seleção italiana e o retrocesso que este revés causou ao futebol e, em alguns destes discursos, o resultado obtido pela seleção brasileira de 1994 é desprezado como forma de se glorificar a forma de jogar da seleção brasileira de 1982, vide, uma vez mais, as palavras de Mauro Beting:

A derrota daquela seleção foi terrível para o futebol, já que institucionalizou a praga pragmática de se jogar pelo resultado. [...]Eu trocaria os títulos de 94 e 2002 pelo de 82. Seria um baitafavor para o futebol, não só brasileiro, mas mundial. [...] Mil vezes rever 82 do que os jogos de 94 e $2002 .^{61}$

\footnotetext{
${ }^{59}$ A título de ilustração, no dia 17 de outubro de 2017, o treinador da seleção brasileira, Tite, em sua participação no programa Boa Noite Fox, do canal Fox Sports, foi perguntado por Paulo Vinícius Coelho, um dos entrevistadores: “Ganhar como 94 ou perder como 82?". De forma um tanto quanto evasiva, Tite respondeu que preferia ganhar como em 2002.

${ }^{60}$ BETING. Prefácio, p. 9.

${ }^{61}$ ROMAN; ZANATA. Sarriá 82, p. 125.
} 
É válido acionar novamente a obra de Rocha e Costa (2014), pois, nesta, ao discorrerem sobre o legado da seleção brasileira de 1994, a seleção brasileira de 1982 é tomada como contraste. Se a valorização da seleção de 1982 se sustenta na sua forma de jogar tida como "verdadeiramente" brasileira, a valorização do legado da seleção de 1994 se dá pela vitória em si, pois esta teria livrado o futebol brasileiro do peso originado justamente pelo revés de 1982. Daí os autores concluírem pedindo consideração pela seleção brasileira de 1994, "que tirou um peso colossal dos ombros do futebol brasileiro. Chutando para escanteio os fantasmas de Sarriá e o 'complexo de vira-latas' que teimava em voltar. [...] É pelo legado que os campeões mundiais de 1994 merecem ser lembrados. E também respeitados”. ${ }^{62}$

É notável a intensidade com que as representações sobre a seleção brasileira de 1994 participam da construção da seleção brasileira de 1982 como uma equipe a ser celebrada. Escrevendo a orelha do livro 82: uma Copa / 15 histórias (2013), o ex-jogador Tostão inicia sua apresentação mencionando a seleção brasileira de 1994 e Dunga, o capitão desta equipe: “Oracional, pragmático e operatório Dunga disse, várias vezes, que não entendia porque a Seleção Brasileira de 1982, que foi eliminada nas quartas de final, é muito mais festejada que a de 1994, campeã do mundo". 63 A dúvida que Tostão apresenta como sendo de Dunga surge na forma de pergunta nas palavras de Luís Simon, também na orelha de uma obra sobre a seleção brasileira de 1982: "Por que, quando buscamos escolher os melhores times de todos os tempos, invariavelmente os derrotados de 1982 têm mais votos do que os campeões de 1994?". ${ }^{64}$ Aqui, é míster destacar que o livro As 22 seleções que mais encantaram ao longo da história (2013) não lista a seleção brasileira de 1994 entre as escolhidas, enquanto exalta que na seleção brasileira de 1982, "Zico e Falcão protagonizavam o espetáculo, acompanhados pelos virtuoses Sócrates, Cerezo, Júnior e Leandro, que juntamente com o explosivo Éder deixavam os torcedores do mundo inteiro extasiados". ${ }^{65}$ Por isso, segue Paulo Maurício Maia,

\footnotetext{
${ }^{62}$ ROCHA; COSTA. É Tetra!, p. 172.

63 TOSTÃO. 82: uma Copa / 15 histórias, orelha do livro.

${ }^{64}$ SIMON. Telê e a seleção de 82, orelha do livro.

${ }^{65}$ MAIA. As 22 seleções que mais encantaram ao longo da história, p. 76.
} 
mesmo "derrotada, a Seleção de Telê Santana saiu da Copa consagrada e entrou para a história como uma das melhores equipes de todos os tempos". 66

Outro trabalho que aborda a questão levantada acima por Simon é o livro $A s$ melhores seleções brasileiras de todos os tempos (2010), escrito por Milton Leite, que escolhe seis equipes como as melhores da mais do que centenária história da seleção brasileira. São elas: todas as seleções que foram campeãs da Copa do Mundo - ou seja, as de 1958, 1962, 1970, 1994 e 2002 - e a seleção de 1982, única não campeã mundial presente na obra. Segundo Leite, a inclusão da seleção brasileira de 1982 na lista "provavelmente será motivo de polêmica, já que para muitos torcedores e especialistas, time bom é o que vence" ${ }^{67}$ No entanto, o que se percebe em suas próprias argumentações é que se há algum intruso no panteão das melhores seleções brasileiras da história este é o "econômico time de 1994", ${ }^{6}$ e não a seleção brasileira de 1982, representada como um time "com qualidade de campeão, mas que não chegou ao título" . ${ }^{69}$ Outro tópico que possibilita enxergar a seleção brasileira de 1982 como sendo mais comemorada por Leite do que a de 1994 encontra-se nos títulos escolhidos pelo autor para narrar as campanhas dessas duas seleções: "Show termina sem taça" é o título do capítulo sobre a seleção de 1982, enquanto "Pragmatismo conquista o tetra" é o da seção dedicada à seleção de 1994. Uma comparação entre os títulos selecionados por Leite permite interpretar que uma das representações recorrentes sobre a seleção brasileira de 1982 é a de que, mesmo sem ser campeã, era capaz de atuações tão espetaculares que podem ser definidas como shows, enquanto a seleção brasileira de 1994, apesar de ter conquistado o título mundial, o fez com um estilo de jogo pragmático.

Seja como forma de exaltar o modo de jogar da seleção brasileira de 1982, seja para destacar as consequências negativas da Tragédia do Sarriá, a seleção brasileira de 1994 é um dos símbolos mais acionados em depoimentos dos jogadores do time brasileiro de 1982. 0 atacante Serginho Chulapa, por exemplo, menospreza o desempenho de 1994 ao mesmo tempo em que celebra o brilho das apresentações de 1982: “A seleção vinha encantando o mundo, não apenas o Brasil.

\footnotetext{
${ }^{66}$ MAIA. As 22 seleções que mais encantaram ao longo da história, p. 77.

${ }^{67}$ LEITE. As melhores seleções brasileiras de todos os tempos, p. 8.

${ }^{68}$ LEITE. As melhores seleções brasileiras de todos os tempos, p. 7.

${ }^{69}$ LEITE. As melhores seleções brasileiras de todos os tempos, p. 7.
} 
Vínhamos de vitória espetacular sobre a Argentina. Em 94 o Brasil ganhou de 1 a 0, empatou aqui e ali, e foi campeão mundial. Mas em 82, com excepcionais jogadores, não ganhamos". ${ }^{70}$ Já para o zagueiro Luisinho, a derrota em 1982 para a seleção italiana "causou efeito negativo para o Brasil. Veio a era Parreira, de só jogar pelo resultado. Esquecemos de jogar futebol. E o mundo seguiu a Itália, com futebol mais defensivo, de jogar só no contra-ataque".71 Também mencionando Carlos Alberto Parreira, treinador da seleção brasileira de 1994, o meio-campista Toninho Cerezo afirma que após 1982 a forma de jogar da equipe brasileira perdeu em beleza por se aproximar da italiana: "O futebol perdeu certo encanto porque a Itália tinha uma mentalidade um pouco alemã. Basta ver o Parreira: pelo que conheci dele, se espelhava no setor defensivo da Alemanha". ${ }^{72}$

Por fim, argumenta-se que no processo de produção de representações sobre a seleção brasileira de 1982 como símbolo do futebol-arte, a Tragédia do Sarriá surge construída tanto como um ponto de inflexão na história do futebol brasileiro quanto como uma injustiça. Primeiramente, a Tragédia do Sarriá surge construída como um ponto de inflexão no sentido de que, a partir deste episódio, a seleção brasileira teria abandonado o futebol-arte - visto como "aquele tipo de futebol [que] era mais brasileiro que tudo. Era o futebol que é nossa identidade" ${ }^{73}$ e passado a se valer da sua antítese, o futebol de resultados. Daí a contundência de Ruy Castro ao afirmar que, "para muitos, a derrota do Brasil naquela Copa decretou o fim do futebol-arte". ${ }^{74}$ Para Helena Jr., recordar a seleção brasileira de 1982 é como "um resgate oportuno do traço mais característico da personalidade singular do nosso futebol, hoje já tão indefinido pela ação corrosiva do tal do futebol de resultados instalado justamente a partir da derrota daquele time para a pragmática Itália". ${ }^{75}$ No mesmo tom, Andrade assevera: "Ninguém pode negar que após a Copa de 1982 houve um generalizado empobrecimento de nosso futebol em seu todo". ${ }^{76}$ Tomando a seleção brasileira como metáfora da nação, Marcelo Tieppo

\footnotetext{
${ }^{70}$ FALCÃO. Brasil 82: O time que perdeu a Copa e conquistou o mundo, p. 74.

${ }^{71}$ FALCÃO. Brasil 82: O time que perdeu a Copa e conquistou o mundo, p. 62.

72 FALCÃO. Brasil 82: O time que perdeu a Copa e conquistou o mundo, p. 66.

${ }^{73}$ BETING, Apresentação, p. 12.

${ }^{74}$ CASTRO. O trauma da bola, orelha do livro.

${ }^{75}$ HELENA JR. Apresentação, p. 10.

${ }^{76}$ ANDRADE. A falta que faz um gol, p. 47.
} 
lamenta que "o Brasil nunca mais foi Brasil dentro de campo, depois da tragédia no estádio Sarriá, em Barcelona". 77

Em segundo lugar, sugere-se que a Tragédia do Sarriá é construída como uma injustiça, pois a seleção brasileira de 1982 é representada como uma equipe que, por praticar o futebol-arte, era tão encantadora, espetacular e superior às adversárias que merecia ter alcançado a glória de ser campeã da Copa do Mundo. Lendo depoimentos dos jogadores da seleção brasileira de 1982, percebe-se que uma das formas mais comuns de se defender a Tragédia do Sarriá como uma injustiça é afirmar que a derrota diante da seleção italiana foi uma fatalidade, de modo que se o confronto se repetisse em outras oportunidades o resultado certamente seria de vitória dos brasileiros, como exemplificam as - um tanto quanto hiperbólicas - palavras do ponta-esquerda Éder: “Aquilo foi um aborto da natureza. Acontece de cem em cem anos". ${ }^{78}$ Jogador reserva da equipe brasileira, Paulo Isidoro, de forma um pouco menos efusiva, segue a mesma ideia: "Se jogássemos mais nove vezes, íamos ganhar as nove". ${ }^{79}$ Segundo Mauro Betting, a injustiça da derrota é tamanha que esse tipo de discurso surgiria até mesmo por parte de jogadores da vencedora seleção italiana: “'Se jogássemos vinte vezes, perderíamos 19. Menos naquele dia', disse Marco Tardelli, meia daquela Itália cirúrgica”. ${ }^{80}$

Responsabilizar o regulamento do torneio foi outro modo encontrado para se afirmar a injustiça da derrota da seleção brasileira de 1982. Para o meiocampista Toninho Cerezo, aquele time brasileiro era "um time feito para ganhar. Infelizmente foi uma competição curta. Se fosse uma competição longa, a gente teria saído com o título". ${ }^{81} \mathrm{Na}$ mesma rota, o lateral Leandro recorda: "Estávamos jogando um futebol maravilhoso, encantando o mundo, todos estavam de acordo. Perdemos um jogo que não tinha como recuperar. Se fosse um campeonato longo, seríamos campeões, sem dúvida. [...] Mas o que fazer? Nem sempre o melhor ganha". ${ }^{2}$

\footnotetext{
${ }^{77}$ TIEPPO. Prefácio, p. 11.

${ }^{78}$ FALCÃO. Brasil 82, p. 75.

${ }^{79}$ FALCÃO. Brasil 82, p. 78.

${ }^{80}$ BETING. Apresentação, p. 12.

${ }^{81}$ FALCÃO. Brasil 82, p. 66.

${ }^{82}$ FALCÃO. Brasil 82, p. 57.
} 


\section{CONSIDERAÇõES FINAIS}

Quando se completam anos redondos da Tragédia do Sarriá, como foram os casos de 2002 e 2012, verifica-se um notável crescimento na já destacada produção de materiais - documentários, reportagens jornalísticas, livros, peças publicitárias, entre outros - que não apenas festejam a seleção brasileira de 1982 como almejam explicar os motivos desta equipe não ter conquistado a Copa do Mundo. Neste artigo, buscou-se compreender, através da análise de livros publicados no século XXI, centrados na trajetória da seleção brasileira de 1982, de que maneira esta espécie de ânsia por elucidar a Tragédia do Sarriáse relaciona com a construção de representações sobre o estilo de jogo praticado por aquela equipe.

Desde os anos 1930, o estilo de jogo brasileiro surge como um operador simbólico capaz de promoverum fluxo de duplo sentido entre as representações sobre a forma de jogar dos futebolistas e sobre o modo de vida dos brasileiros. Nesta linha, e em diálogo com pesquisas recentes, argumenta-se que a seleção brasileira de 1982 tem sido construída como representante da identidade nacional por praticar o futebol-arte, um estilo de jogo que prima pela criatividade individual, desde seus primeiros momentos de atuação.

A análise de conteúdos simbólicos produzidos neste século sobre a seleção brasileira de 1982 sugere que a construção desta equipe como símbolo do futebolarte é um processo que ainda segue ativo e, inclusive, com algumas características novas se comparado ao que se deu concomitantemente à Copa do Mundo de 1982. Dentre as novidades, o presente artigo se debruçou sobre aquelas que são frutos dos contextos de comparação entre as seleções brasileiras de 1982 e de 1994, dada a frequência com a qual tais comparações se erguem.

O processo de construção da seleção brasileira de 1982 como representante da identidade brasileira por praticar um futebol encantador, espetacular e digno de ser celebrado apresenta como uma de suas etapas mais significativas a simultânea construção da seleção brasileira de 1994 como econômica, pragmática, defensiva e digna de pesar - em síntese, como a negação da forma de jogar vista como "genuinamente" brasileira. Além do mais, há de se destacar ainda o acionamento da seleção brasileira de 1994 como forma de ilustrar o retrocesso experimentado 
pelo futebol nacional após a Tragédia do Sarriá, dado que este evento aparece como um ponto de inflexão a partir do qual a seleção brasileira teria abandonado o futebol-arte e passado a se valer do futebol de resultados.

O estudo aqui realizado contribui para a compreensão da Tragédia do Sarriá como um dos eventos mais rememorados e intrigantes da história do futebol brasileiro ao permitir as seguintes elaborações acerca do estilo de jogo praticado pela seleção brasileira de 1982. Em primeiro lugar, a Tragédia do Sarriá coloca-se como um episódio intensamente recordado, pois foi protagonizado por uma equipe, a seleção brasileira de 1982, que surge atualmente representada não apenas como símbolo do futebol-arte, mas como a última seleção que praticou este estilo de jogo tido como "verdadeiramente" brasileiro e que, por isso, é digna de ser festejada. Nesse processo construtivo da seleção brasileira de 1982 como a última representante da forma de jogar futebol condizente com a identidade nacional, é significativa a participação da seleção brasileira de 1994 na posição de alteridade privilegiada ao ser representada como símbolo do europeizado futebol de resultados. Em segundo lugar, a Tragédia do Sarriá aparece como um acontecimento que exige respostas, na medida em que se constrói a seleção brasileira de 1982 como praticante de um futebol tão espetacular que jamais merecia ter perdido a Copa do Mundo. Nesse processo que representa a seleção brasileira de 1982 como injustiçada pelo encanto que gerava, é relevante, novamente, a presença da seleção brasileira de 1994 como alteridade privilegiada, visto que esta equipe conquistou o título da Copa do Mundo com um estilo de jogo representado como pragmático.

\section{REFERÊNCIAS}

ANDRADE, Jeferson. A falta que faz um gol. Belo Horizonte: Página Aberta Editora, 2002.

BETING, Mauro. Apresentação. In: ROMAN, Gustavo; ZANATA, Renato. Sarriá 82: o que faltou ao futebol-arte?. Rio de Janeiro: Maquinaria, 2012, p. 11-13. 
BETING, Mauro. Prefácio. In: ROCHA, André; COSTA, Michel. É Tetra!: a conquista que ajudou a mudar o Brasil. Rio de Janeiro: Via Escrita, 2014, p. 9-10.

CARMONA, Lédio. Contracapa. In: ROMAN, Gustavo; ZANATA, Renato. Sarriá 82: o que faltou ao futebol-arte?. Rio de Janeiro: Maquinaria, 2012.

CASTRO, Ruy. Contracapa. In: SALDANHA, João. O trauma da bola: a Copa de 82 por João Saldanha. São Paulo, Cosac \& Naify, 2002.

CASTRO, Ruy. Orelha do livro. In: SALDANHA, João. O trauma da bola: A Copa de 82 por João Saldanha. São Paulo: Cosac \& Naify, 2002.

COSTA, Leda. 1982: lágrimas de uma geração de ouro. In: HELAL, Ronaldo; CABO, Alvaro (orgs.). Copas do Mundo: comunicação e identidade cultural no país do futebol. Rio de Janeiro: EdUERJ, 2014, p. 165-193.

DAMATTA, Roberto. Universo do futebol: esporte e sociedade brasileira. Rio de Janeiro: Pinakotheke, 1982.

FALCÃO, Paulo Roberto. Brasil 82: o time que perdeu a Copa e conquistou o mundo. Porto Alegre: AGE, 2012.

FARR, Robert. Representações sociais: a teoria e sua história. In: GUARESCHI, Pedrinho; JOVCHELICH, Sandra. (orgs.) Textos em representações sociais. Petrópolis: Vozes, 1995, p. 31-62.

FREYRE, Gilberto. Foot-ball mulato. Diário de Pernambuco. Recife, 17 jun. 1938.

FREYRE, Gilberto. Casa-grande \& senzala: formação da família brasileira sob o regime da economia patriarcal. Recife: Global Editora, 2003.

GUEDES, Simoni. De criollos e capoeiras: notas sobre o futebol e identidade nacional na Argentina e no Brasil. In: GASTALDO, Édison; GUEDES, Simoni. (orgs.) Nações em campo: Copa do Mundo e identidade nacional. Niterói: Intertexto, 2006, p. 127-146.

GUEDES, Simoni. A produção das diferenças na produção dos "estilos de jogo" no futebol: a propósito de um texto fundador. In: HOLLANDA, Bernardo Borges; Burlamaqui, Luiz Guilherme. (orgs). Desvendando o jogo: nova luz sobre o futebol. Niterói: EDUFF, 2014, p. 153-171.

HELENA JR., Alberto. Apresentação. In: MORA, Marcelo. Telê e a seleção de 82: da arte à tragédia. São Paulo: Publisher Brasil, 2012, p. 9-10.

LEITE, Milton. As melhores seleções brasileiras de todos os tempos. São Paulo: Contexto, 2010.

LISE, Riqueldi; CAPRARO, André; CAVICHIOLLI, Fernando. A Copa do Mundo de 1982 e o "turbilhão de emoções" nas crônicas de Nelson Motta. Revista Brasileira de Ciências do Esporte, Campinas, v. 39, n. 1, 2017, p. 10-16.

MAIA, Paulo Maurício. As 22 seleções que mais encantaram ao longo da história. Rio de Janeiro: Rotativa, 2013.

MORA, Marcelo. Telê e a seleção de 82: da arte à tragédia. São Paulo: Publisher Brasil, 2012. 
MOSCOVICI, Serge. Prefácio. In: GUARESCHI, Pedrinho; JOVCHELICH, Sandra. (orgs.). Textos em representações sociais. Petrópolis: Vozes, 1995, p. 7-14.

MOSCOVICI, Serge. A história e a atualidade das representações sociais. In:

Representações sociais: investigações em psicologia social.

Petrópolis: Vozes, 2009, p. 167-214.

MOSTARO, Filipe; HELAL, Ronaldo. Jornal da Tarde, 06 de julho de 1982: a imagem como construção de sentidos de uma derrota. Discursos fotográficos, Londrina, v. 12, n. 20, jan.-jul. 2016, p. 12-37.

PEREIRA, Mauro Cezar. Orelha do livro. In: ROMAN, Gustavo; ZANATA, Renato.

Sarriá 82: o que faltou ao futebol-arte?. Rio de Janeiro: Maquinaria, 2012.

QUEIROZ, Maria Isaura. Identidade Nacional, Religião, Expressões Culturais: a criação religiosa no Brasil. In: SACHS, Viola. (org.). Brasil \& EUA. Religião e Identidade Nacional. Rio de Janeiro: Graal, 1988, p. 59-93.

ROCHA, André; COSTA, Michel. É Tetra!: a conquista que ajudou a mudar o Brasil. Rio de Janeiro: Via Escrita, 2014.

ROMAN, Gustavo; ZANATA, Renato. Sarriá 82: o que faltou ao futebol-arte?. Rio de Janeiro: Maquinaria, 2012.

SALDANHA, João. O trauma da bola: a Copa de 82 por João Saldanha. São Paulo, Cosac \& Naify, 2002.

SIMON, Luís. Orelha do livro. In: MORA, Marcelo. Telê e a seleção de 82: da arte à tragédia. São Paulo: Publisher Brasil, 2012.

SOARES, Antônio Jorge; LOVISOLO, Hugo. Futebol: a construção histórica do estilo nacional. Revista Brasileira de Ciências do Esporte. Campinas, v. 25, n. 1, 2003, p. 129-143.

TIEPPO, Marcelo. Prefácio. In: MORA, Marcelo. Telê e a seleção de 82: da arte à tragédia. São Paulo: Publisher Brasil, 2012, p. 11-12.

TOSTÃO. Orelha do livro. In: GALLO, Mayrant (org.). 82: uma Copa / 15 histórias. Anajé: Casarão do Verbo, 2013.

VELHO BARRETO, Túlio. Gilberto Freyre e o Futebol-Arte. Revista USP. São Paulo, n. 62, 2004, p. 233-238.

Recebido para publicação em: 01 ago. 2018.

Aprovado em: 01 out. 2018. 